\title{
Kefir exhibits anti-proliferative and pro-apoptotic effects on colon adenocarcinoma cells with no significant effects on cell migration and invasion
}

\author{
NATHALIE KHOURY $^{1 *}$, STEPHANY EL-HAYEK $^{1 *}$, OMAYR TARRAS $^{1}$, \\ MARWAN EL-SABBAN ${ }^{2}$, MIRVAT EL-SIBAI ${ }^{1}$ and SANDRA RIZK ${ }^{1}$ \\ ${ }^{1}$ Department of Natural Sciences, Lebanese American University, Beirut 1102 2801; ${ }^{2}$ Department of Anatomy, \\ Cell Biology and Physiological Sciences, Faculty of Medicine, American University of Beirut, Beirut 1107 2020, Lebanon
}

Received July 5, 2014; Accepted August 20, 2014

DOI: 10.3892/ijo.2014.2635

\begin{abstract}
Kefir, a fermented milk product, exhibits anti-tumoral activity in vivo; yet its mechanism of action remains elusive. Recent studies have focused on the mechanism of action of kefir on cancer cells in vitro. The current study aims at examining the effect of kefir on cell survival, proliferation, and motility of colorectal cancer (CRC) cells. Kefir's anti-cancer potential was tested on CRC cell lines, Caco-2 and HT-29, through cytotoxicity, proliferation, and apoptotic assays. The expression of certain genes involved in proliferation and apoptosis was measured using reverse transcriptase-polymerase chain reaction (RT-PCR) and western blotting. To assess the effect of kefir on cancer metastasis, wound-healing and time-lapse movies, in addition to collagen-based invasion assay, were used. The results show that cell-free fractions of kefir exhibit an anti-proliferative effect on Caco-2 and HT-29 cells. Analysis of DNA content by flow cytometry revealed the ability of kefir to induce cell cycle arrest at the G1 phase. Kefir was also found to induce apoptosis, as seen by cell death ELISA. Results from RT-PCR showed that kefir decreases the expression of transforming growth factor $\alpha(T G F-\alpha)$; and transforming growth factor- $\beta 1(T G F-\beta 1)$ in HT-29 cells. Western blotting results
\end{abstract}

Correspondence to: Dr Sandra Rizk, Department of Natural Sciences, Lebanese American University, P.O. Box 13-5053, Chouran, Beirut 1102 2801, Lebanon

E-mail: sandra.rizk@lau.edu.lb

${ }^{*}$ Contributed equally

Abbreviations: CRC, colorectal cancer; RT-PCR, reverse transcriptase-polymerase chain reaction; HTLV-1, human T-lymphotropic virus type I; EGFR, epidermal growth factor receptor; TGF- $\alpha$, transforming growth factor- $\alpha$; TGF- $\beta 1$, transforming growth factor- $\beta 1$; IC50, inhibitory concentration 50; EF, enrichment factor

Key words: kefir, colorectal cancer, apoptosis, cell motility, cell invasion revealed an upregulation in Bax:Bcl-2 ratio, confirming the pro-apoptotic effect of kefir, and an increase in p53 independent-p21 expression upon kefir treatment. MMP expression was not altered by kefir treatment. Furthermore, results from time-lapse motility movies, wound-healing, and invasion assays showed no effect on the motility of colorectal as well as breast (MCF-7 and MB-MDA-231) cancer cells upon kefir treatment. Our data suggest that kefir is able to inhibit the proliferation and induce apoptosis in HT-29 and Caco-2 CRC cells, yet it does not exhibit a significant effect on the motility and invasion of these cells in vitro.

\section{Introduction}

Kefir is a well-known fermented milk product obtained by the fermentation of milk with kefir grains. It is highly consumed in many countries, mostly in Eastern Europe, but also in Asia and America $(1,2)$. Around the world, kefir is manufactured and marketed as a refreshing, slightly alcoholic beverage, under different names (Kephir, Kiaphur, Kefer, Kepi and Kippi) (1-3).

Kefir grains are a white, soft, gelatin-like mass composed of bacteria and yeast existing in a matrix of proteins, fat, and polysaccharides, with kefiran being the most important water-soluble polysaccharide (4). Around 50 types of these microorganisms co-exist in a symbiotic relationship in the kefir grains: these include lactic acid bacteria, yeasts, streptococci, lactococci and infrequently acetic acid bacteria among others (5).

It was always assumed among Bulgarian farmers that kefir held special healing powers, and they believed that their longevity was attributed to their ingestion of kefir (6). Kefir has been made in the Caucasus Mountains for hundreds of years, yet it was kept in secrecy within tribes who held it as their legacy, and not until recently have kefir grains been distributed to different regions of the world (2). Since then, many health benefits have been attributed to kefir, including its ability to stimulate the immune system (7), improve lactose digestion in lactose-intolerant individuals (8), decrease serum cholesterol levels (9), provide resistance against enteric and diarrheal diseases (10), act as an antifungal and antibacterial 
agent against pathogenic organisms (12), as well as possessing an anti-tumoral activity (11).

The first publication to show antitumoral activity of a water-soluble polysaccharide (KGF-C) separated from kefir grains was published in 1982 by Shiomi et al. The study showed that KGF-C prevented the growth of Ehrlich carcinoma or Sarcoma 180 when administered orally or peritoneally $(13,14)$. Later studies determined that KGF-C polysaccharide enhances the immune system by affecting T- and not B-cell action (15). Additionally, studies have also shown that Lewis lung and Ehrlich ascites carcinoma were inhibited upon the oral administration of kefir $(16,17)$. Moreover, kefir produced from soy milk and cow's milk considerably repressed tumor growth in mice injected with Sarcoma 180 as compared to unfermented milk. Microscopic observations suggested that the tumor size was decreased due to apoptosis (6). Yet the mechanism of action behind kefir's anti-tumoral activity remained elusive.

Recently, in vitro studies were performed to determine whether kefir has any direct effect on cancer cells. Cell-free kefir fractions exhibited an anti-proliferative effect on human mammary cancer cells (MCF-7) but did not affect normal mammary epithelial cells (11). Similarly, previous studiesdone in our laboratory showed that cell-free kefir fractions have anti-proliferative and pro-apoptotic effects on human T-lymphotropic virus type I (HTLV-1) positive and HTLV-1 negative T-lymphocytes but did not exert any effect on lymphocytes removed from the peripheral blood of healthy individuals $(18,19)$. Among the few studies that examine the anti-tumoral activity of kefir, only one study discussed the anti-metastatic ability of kefir on cancer cells in vivo. A study in 2000 by Furukawa et al showed that when the water-soluble polysaccharide fraction from kefir grains is administered orally either before or after tumor transplantation, it inhibited the pulmonary metastasis of Lewis lung carcinoma. Similarly, the water insoluble fraction of kefir grains was able to prevent metastasis in mice injected with the highly metastatic B16 melanoma (20).

In 2013, the American Cancer Society ranked colorectal cancer (CRC) as the third leading cause of cancer-related mortalities in the US in both men and women. It was estimated that by the end of $2013,>50,000$ death cases will arise due to CRC (21). The sequence of events leading to the formation of CRC takes place over a period of 10-15 years allowing sufficient time for chances to screen, properly interfere, and to potentially save the lives of more patients $(22,23)$. Significant successes have been achieved through targeted therapy in the treatment of CRC (24-26). Yet, by the time people are diagnosed with CRC, $25 \%$ of patients would have already developed metastasis. Among these patients with metastatic CRC, 50\% will survive (27). Whether it initially exists during diagnosis, or occurs during treatment or relapse, metastasis remains the primary cause of death in cancer patients $(28,29)$. Targeting any step in the metastatic process such as motility or invasion can limit the metastatic ability of cancer cells and retain them in their primary location.

The current study aims at examining the effect of cell-free fractions of kefir on the viability, proliferation, apoptosis and motility of CRC cells in vitro, and determining the underlying mechanism of action.

\section{Materials and methods}

Cell line and cell culture. Human colorectal adenocarcinoma cell lines (Caco-2 and HT-29) and human breast cancer cell lines (MCF-7 and MDA-MB231), obtained from ATCC (American Type Culture Collection), were cultured in DMEM medium supplemented with $10 \%$ FBS and $100 \mathrm{U}$ penicillin/streptomycin at $37^{\circ} \mathrm{C}$ and $5 \% \mathrm{CO}_{2}$ in a humidified chamber.

Antibodies and reagents. Mouse monoclonal IgG anti- $\beta$-actin, anti-Bax, anti-Bcl2, anti-p53, anti MMP-2, and anti-MMP-9 antibodies and rabbit polyclonal anti-p21 were obtained from Santa Cruz Biotechnology, Inc. Anti-mouse and anti-rabbit IgG HRP-conjugated secondary antibodies were obtained from Promega.

Preparation of kefir cell-free fraction and milk. Pasteurized skimmed milk $(150 \mathrm{ml})$ was inoculated with kefir grains $(50 \mathrm{~g})$. Inoculated milk samples were incubated at $20^{\circ} \mathrm{C}$ for $24 \mathrm{~h}$ in a sealed-glass container. At the end of fermentation, the milk was strained to remove the kefir grains. The yeast and bacteria in the filtrate were removed by centrifugation $(35,000 \mathrm{rpm}$ for $10 \mathrm{~min}$ at $4^{\circ} \mathrm{C}$ ). The supernatant was stored at $-20^{\circ} \mathrm{C}$ until needed for treatment of cells. On the day of treatment, the kefir supernatant was thawed and then passed through a $0.22-\mu \mathrm{m}$ filter (Millipore). This cell-free fraction of fermented milk, also termed kefir, was applied directly to the cells in different volumes to establish the different concentrations required.

Non-inoculated milk samples were similarly prepared but passed consecutively through a $0.45-\mu \mathrm{m}$ then $0.22-\mu \mathrm{m}$ filter (Millipore).

Cytotoxicity: trypan blue exclusion method. HT-29 and Caco-2 cells were grown in 24-well plates (growth area: $2 \mathrm{~cm}^{2}$ ) at a density of $2 \times 10^{6}$ cells $/ \mathrm{ml}$. Cells were treated with milk and kefir at the following concentrations $(\mathrm{v} / \mathrm{v}): 0$, $5,10,15$, and $20 \%$. After 24, 48, and $72 \mathrm{~h}$, the supernatant from each well was collected, cells were washed with phosphate-buffered saline (PBS), and the washes were added to the supernatant of each well. Cells were then trypsinised and collected separately from the well contents and PBS. From each collection tube $20 \mu \mathrm{l}$ were mixed with $20 \mu \mathrm{l}$ of trypan blue (Sigma-Aldrich). This mixture was placed in a counting chamber under the microscope and the percentage of viable cells was reported.

Proliferation: cell proliferation reagent (WST-1). HT-29 and Caco-2 cells were seeded in 96-well plates (growth area: $0.6 \mathrm{~cm}^{2}$ ) at a concentration of $1 \times 10^{6}$ cells $/ \mathrm{ml}$. After $24 \mathrm{~h}$ of seeding, cells were treated with $0,5,10,15$, and $20 \%$ milk and kefir (v/v). For every milk and kefir concentration, a blank well was prepared, containing only media and the corresponding volume of kefir or milk. After 24, 48, and $72 \mathrm{~h}, 10 \mu \mathrm{l}$ of cell proliferation reagent (WST-1; Roche) was added to each well. The plates were put in a humidified incubator $\left(37^{\circ} \mathrm{C}\right)$ for $1.5 \mathrm{~h}$. Absorbance was then read at $450 \mathrm{~nm}$. The absorbance of the each blank well was subtracted from the corresponding sample well. The results were normalized to the untreated controls, and the percent proliferation was reported. 
Cell cycle analysis: flow cytometry. Caco-2 and HT-29 cells were seeded in 6-well plates (growth area: $9.5 \mathrm{~cm}^{2}$ ). Treatment was done for $24 \mathrm{~h}$, with $10 \%$ milk and kefir. After treatment, cells were trypsinized and detached, then centrifuged at $1,200 \mathrm{rpm}$ at $5^{\circ} \mathrm{C}$ for $5 \mathrm{~min}$. The pellet was washed in $1 \mathrm{ml}$ of ice-cold PBS, centrifuged, and resuspended again in $1 \mathrm{ml}$ of ice-cold PBS. Ethanol was then added to a final concentration of $70 \%$. The fixed cells were left overnight at $40^{\circ} \mathrm{C}$. The following day, cells were centrifuged and washed with PBS. The pellet was resuspended in $500 \mu \mathrm{l}$ of binding buffer, and then $10 \mu$ l of propidium iodide (PI) was added to each sample. The samples were incubated in the dark for $10 \mathrm{~min}$.

Cells were analyzed using an Accuri C6 flow cytometer (Accuri Cytometers Inc.), which indicated the distribution of the cells into their respective cell cycle phases based on their DNA content. Cell DNA content was determined by CFlow ${ }^{\circledR}$ software. An increase in cells in the pre-G phase is indicative of an increase in cell death. The percentage of cells in the sub-G0/G1 phase was compared to that of the control.

Cell death ELISA. HT-29 and Caco-2 cells were grown in 96-well plates (growth area: $0.6 \mathrm{~cm}^{2}$ ) at $1 \times 10^{5}$ cells $/ \mathrm{ml}$. After $24 \mathrm{~h}$, cells were treated with relative concentrations $(\mathrm{v} / \mathrm{v})$ : $0,5,10$, and $15 \%$. After 24 or $48 \mathrm{~h}$, cells were lysed with lysis buffer, and incubated for $30 \mathrm{~min}$ at room temperature. The plates were then centrifuged for $10 \mathrm{~min}$ at $200 \mathrm{~g}$. The supernatant $(20 \mu \mathrm{l})$ was placed in streptavidin-coated microtiter plates, followed by the addition of biotin-labeled anti-histone and peroxidase-conjugated anti-DNA antibodies. The anti-histone antibody, bound to the plate via biotin-streptavidin, also bound histones from released nucleosomes. The plate was then incubated at room temperature for $2 \mathrm{~h}$, after which 2,2'-azino-di[3-ethylbenzthiazolin-sulfonate] (ABTS) was added as a substrate for peroxidase enzyme. Enrichment factor $(\mathrm{EF})$ was calculated as the recorded absorbance of each sample, divided by that of the untreated cells, according to manufacturer's instructions (Roche).

Western blotting. Cell lysates were prepared by scraping the cells in a sample buffer consisting of $4 \%$ SDS, $10 \%$ $\beta$-mercaptoethanol, 20\% glycerol, $0.004 \%$ bromophenol blue, and $0.125 \mathrm{M}$ Tris- $\mathrm{HCl}$ at $\mathrm{pH}$ 6.8. The resulting lysates were boiled for $5 \mathrm{~min}$. Protein samples were separated by SDS-PAGE on $10 \%$ (for $\beta$-actin, p53, Mmp-2, and Mmp-9) or $12 \%$ (for Bax, Bcl-2, and p21) gels and transferred to PVDF membranes overnight at $30 \mathrm{~V}$. The membranes were then blocked with 5\% BSA in PBS containing 0.1\% Tween-20 for $1 \mathrm{~h}$ at room temperature and incubated with primary antibody at a concentration of 1:1,000 for $2 \mathrm{~h}$ at room temperature. After the incubation with the primary antibody, the membranes were washed and incubated with secondary antibody at a concentration of 1:1,000 for $1 \mathrm{~h}$ at room temperature. The membranes were then washed, and the bands visualized by treating the membranes with western blotting enhanced chemiluminescent reagent ECL (GE Healthcare). The results were obtained on X-ray film (Agfa Healthcare). The levels of protein expression were compared by densitometry using the ImageJ software.

Reverse-transcription PCR. Cells were grown in 6-well plate at density of $1 \times 10^{6}$ cells $/ \mathrm{ml}$. After $24 \mathrm{~h}$, cells were treated with
0,5 , and $10 \%$ cell-free fractions of kefir for $24 \mathrm{~h}$, after which total RNA was extracted using RNeasy extraction kit (Qiagen) according to manufacturer's instruction. Reverse transcriptasepolymerase chain reaction (RT-PCR) was used to amplify RNA of $\beta$-actin $(A C T B)$, transforming growth factor $\alpha(T G F-\alpha)$ and transforming growth factor- $\beta 1(T G F-\beta 1)$. RNA $(2 \mu \mathrm{g})$ was converted to cDNA using the OneStep RT-PCR kit (Qiagen) as described by the manufacturer. All gene-specific primers designed to detect cDNA were obtained from Sigma-Aldrich. Primer sequences used were: $\beta$-actin, forward: 5'-ATGAA GATCCTGACCGAGCGT-3', and reverse: 5'-AACGCAGC TCAGTAACAGTCCG-3'; TGF- $\alpha$, forward: 5'-ATGTTGTT CCCTGCAAGTCC-3', and reverse: 5'-ACTATGGAGAGG GGTCGCTT-3'; TGF- $\beta$, forward: 5'-GAAGTCACCCGCGT GCTAATGG-3', and reverse: 5'-GGATGTAAACCTCGGA CCTGTGTG-3'. The RT-PCR reagents and thermal cycler conditions were used according to manufacturer's instruction with an annealing temperature of $52^{\circ} \mathrm{C}$ for $\beta$-actin, $48^{\circ} \mathrm{C}$ for TGF- $\alpha$ and $50^{\circ} \mathrm{C}$ for $T G F-\beta 1$ for $1 \mathrm{~min}$. From the PCR product, $10 \mu \mathrm{l}$ were run on $0.8 \%$ agarose gel stained with ethidium bromide at $100 \mathrm{~V}$ for $30 \mathrm{~min}$. The resulting bands were visualized under UV light and photographed. $\beta$-actin was used as a loading control.

Wound healing. Cells were grown to confluence on culture plates and a wound was made in the monolayer with a sterile pipette tip. After wounding, the cells were washed twice with PBS to remove debris and fresh medium was added. Phase-contrast images of the wounded area were taken at 0 and 21 or $24 \mathrm{~h}$ after wounding. Wound widths were measured at 11 different points for each wound, and the average rate of wound closure was calculated in $\mu \mathrm{m} / \mathrm{h}$ using ImageJ software.

Motility assay. For motility analysis, images of cells moving randomly in serum were collected every $60 \mathrm{sec}$ for $2 \mathrm{~h}$ using a 20x objective. During imaging, the temperature was controlled using a Nikon heating stage which was set at $37^{\circ} \mathrm{C}$. The medium was buffered using HEPES and overlayed with mineral oil. The speed of cell movement was quantified using the ROI tracker plugin in ImageJ software, which was used to calculate the total distance travelled by individual cells. The speed was then calculated by dividing this distance by the time (120 min) and reported in $\mu \mathrm{m} / \mathrm{min}$. The speed of at least 10 cells for each condition was calculated.

Invasion assay. Cells were grown in 6-well plates. After $24 \mathrm{~h}$, cells were treated with 0,5 , and $10 \%$ of kefir for another $24 \mathrm{~h}$. Invasion assay was performed following treatment period using the collagen-based invasion assay (Millipore) according to manufacturer's instructions. Briefly, $24 \mathrm{~h}$ prior to assay, cells were starved with serum free medium. Cells were harvested, centrifuged and then resuspended in quenching medium (serum free). Cells were then brought to a concentration of $1 \times 10^{6}$ cells $/ \mathrm{ml}$. Inserts were rehydrated with $300 \mu \mathrm{l}$ of serum free medium for $30 \mathrm{~min}$ at room temperature, $250 \mu \mathrm{l}$ of media was then removed from inserts and $250 \mu \mathrm{l}$ of cell suspension was added. Inserts were then placed in a 24-well plate, and $500 \mu \mathrm{l}$ of complete media was added to the lower wells. Plates were incubated for $24 \mathrm{~h}$ at $37^{\circ} \mathrm{C}$ in a 

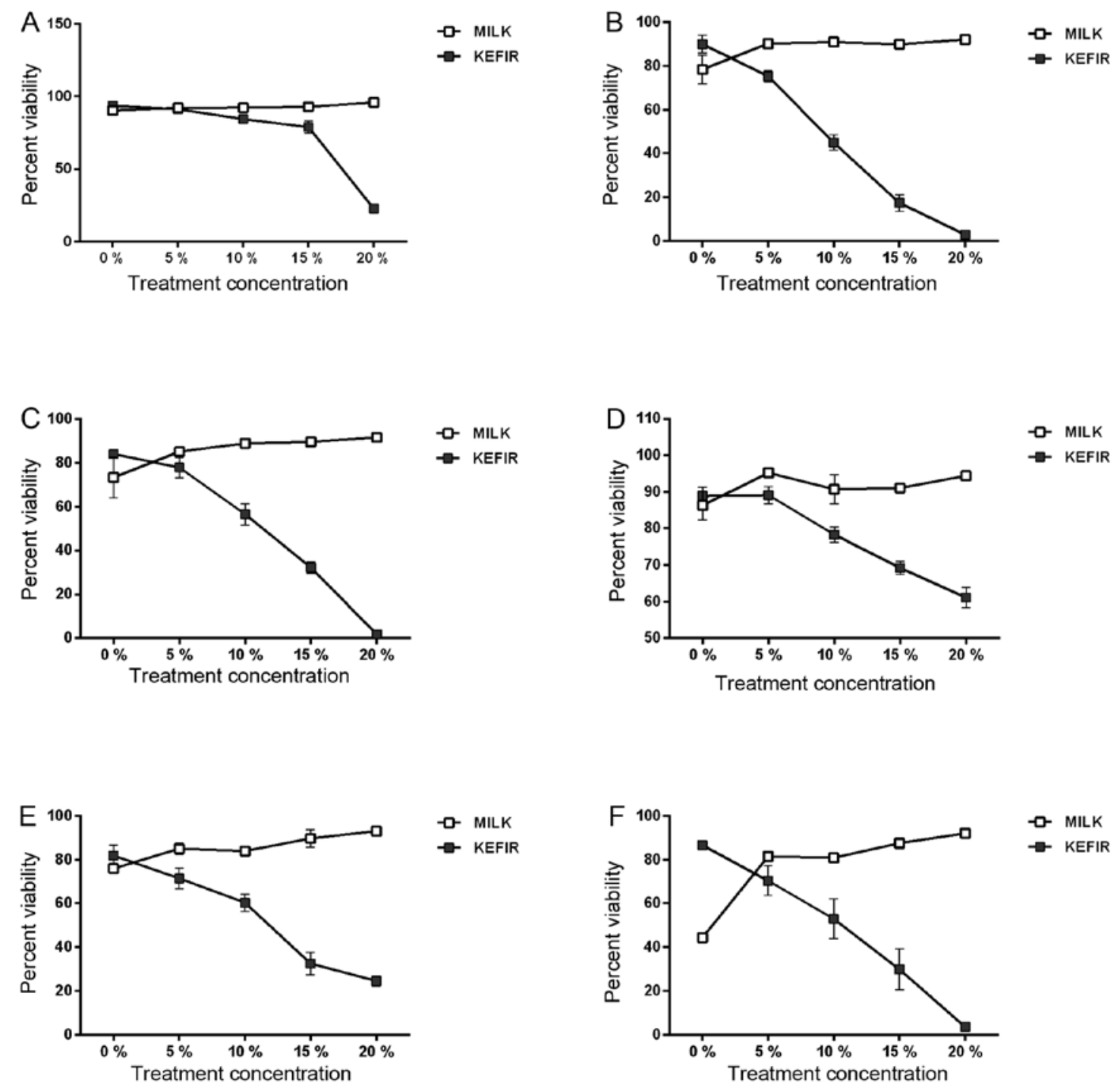

Figure 1. Effect of kefir on viability of colorectal cancer (CRC) cell lines using trypan blue assay. Viability of Caco-2 cells after (A) $24 \mathrm{~h}$, (B) $48 \mathrm{~h}$, and (C) $72 \mathrm{~h}$ of treatment with different concentrations of milk and kefir cell-free fractions. Viability of HT-29 cells after (D) $24 \mathrm{~h}$, (E) $48 \mathrm{~h}$, and (F) $72 \mathrm{~h}$ of treatment with different concentrations of milk and kefir cell-free fractions. Results are reported as the percent of viable cells out of the total number of cells (dead and alive). Data represent mean \pm SEM from three independent experiments.

$\mathrm{CO}_{2}$ incubator. Later, inserts were stained for $20 \mathrm{~min}$ at room temperature with $400 \mu 1$ of cell stain provided with the kit. Stain was then extracted with extraction buffer. The extracted stain $(100 \mu \mathrm{l})$ was then used for colorimetric measurement using a plate reader. Optical density was measured at $560 \mu \mathrm{m}$.

Statistical analysis. Allreported results represent average values from three independent experiments. The error estimates are given as mean \pm SEM. The $p$-values were calculated by $\mathrm{t}$-tests or $\chi^{2}$ tests depending on the experiment, using the VassarStats: Website for Statistical Computation (http://vassarstats.net/).

\section{Results}

Kefir treatment reduces the viability of CRC cells. To assess kefir's cytotoxicity on the two cell lines, we began by determining the percentage viability after treating the cells with increasing kefir concentrations. Upon kefir treatment, the viability of the cells decreased in a time- and dose-dependent manner.
Results demonstrated that kefir's inhibitory concentration 50 (IC50) for Caco-2 cells ranges between 10, 12, and $18 \%(\mathrm{v} / \mathrm{v})$ at 72, 48, and $24 \mathrm{~h}$, respectively (Fig. 1A-C). For HT-29 cells, the IC50 was only reached at 48 and $72 \mathrm{~h}$ of treatment, where it was determined to be 12 and 10\%, respectively (Fig. 1D-F). Past the IC50, the viability of both cell lines decreased significantly $(\mathrm{p}<0.05)$. Cytotoxicity levels were shown to be dose- and time-dependent. The viability of both cell lines, 24, 48, and $72 \mathrm{~h}$ after treatment with various milk concentrations was not reduced, but rather, a slight increase in percentage viability was detected, significant compared to kefir (p<0.05) (Fig. 1A-F).

The viability of both cell lines was not reduced $6 \mathrm{~h}$ post-treatment (data not shown), suggesting that the cells were dying through apoptosis rather than necrosis.

Kefir treatment reduces proliferation of Caco-2 and HT-29 cells. The effect of kefir on proliferation of CRC cells was determined by the activity of mitochondrial dehydrogenases. 

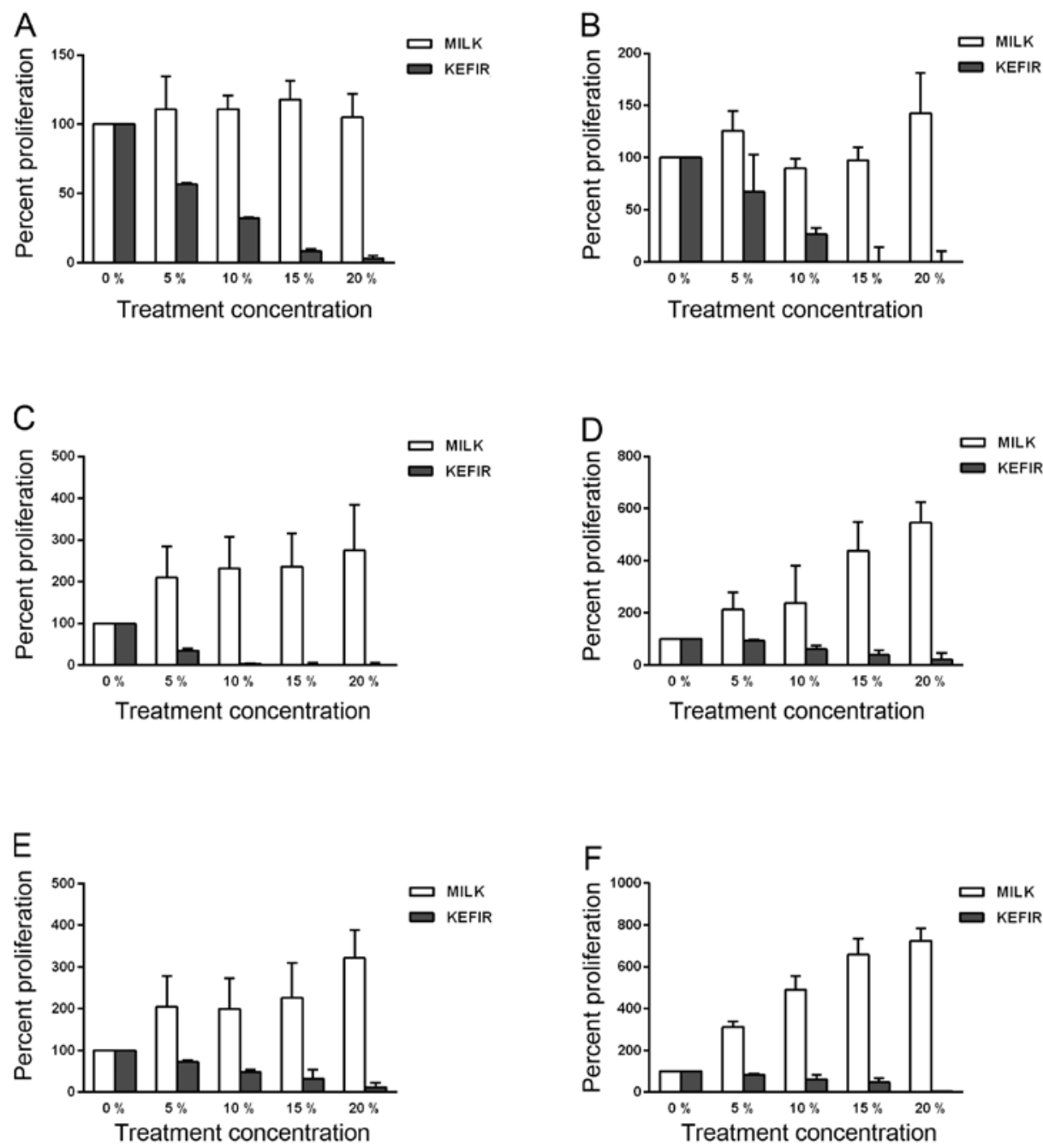

Figure 2. Effect of kefir on the proliferation of colorectal cancer (CRC) cell lines. Proliferation of Caco-2 cells after (A) $24 \mathrm{~h}$, (B) $48 \mathrm{~h}$, and (C) $72 \mathrm{~h}$ of treatment with different concentrations of milk and kefir cell-free fractions. Proliferation of HT-29 cells after (D) $24 \mathrm{~h}$, (E) $48 \mathrm{~h}$, and (F) $72 \mathrm{~h}$ of treatment with different concentrations of milk and kefir cell-free fractions. Results were normalized to the untreated cells. Data represent mean \pm SEM from three independent experiments

Results have shown that kefir significantly inhibited the proliferation of HT-29 and Caco-2 cells (p<0.05) (Fig. 2A-F). At the kefir concentrations where the IC50 was calculated in the trypan blue exclusion method with Caco- 2 cells, the recorded decrease in proliferation was $95 \%$ at $24 \mathrm{~h}, 94 \%$ at $48 \mathrm{~h}$, and $97 \%$ at $72 \mathrm{~h}$ compared to untreated cells (Fig. 2A-C).

HT-29 cells as well showed significant inhibition of proliferation upon kefir treatment, even though the effect was slightly less than that exhibited by the Caco-2 cells (Fig. 2D-F). At the concentrations corresponding to the IC50, the percent decrease was calculated to be $60 \%$ at $48 \mathrm{~h}$, and $38 \%$ at 72 h (Fig. 2E and F).

All cells treated with milk showed a significant increase in proliferation, compared to the untreated and kefir-treated cells $(\mathrm{p}<0.05)$. Hence, kefir treatment significantly reduces proliferation of CRC cell lines in a time- and dose-dependent manner.

Kefir induces cell cycle arrest at the G1 phase. After verifying that kefir inhibited cell proliferation in CRC cells, we aimed to evaluate whether this effect was through an induction of cell cycle arrest, using flow cytometry. After analyzing the cell's DNA content, cells were assigned to their respective phases: sub-G0/G1 cells were $<2 \mathrm{n}, \mathrm{G} 0 / \mathrm{G} 1$ cells were $2 \mathrm{n}$, and $\mathrm{S} / \mathrm{M}$ phase cells were $>2 \mathrm{n}$.

Consistent with the results of the proliferation assay, the sub-G0/G1 population of Caco- 2 cells increased from 14 to $5.2 \%$ as a result of $10 \%$ kefir treatment, while the $\mathrm{S} / \mathrm{M}$ phase cells decreased from 15.5 to $3.6 \%$ (Fig. 3A and C). The same pattern of cell cycle shift was seen upon treatment of HT-29 cells with $10 \%$ kefir. The sub-G0/G1 population increased from 13.9 to $52.7 \%$, accompanied by a significant decrease in $\mathrm{S} / \mathrm{M}$ phase population from 24.8 to $1.5 \%$ (Fig. 3D and F). When these cells were treated with $10 \%$ milk, a slight increase in sub-G0/G1 population and a noticeable increase in $\mathrm{S} / \mathrm{M}$ were detected in both Caco-2 and HT-29 cells (Fig. 3A, B, $\mathrm{D}$ and $\mathrm{E})$, significant compared to kefir treatment $(\mathrm{p}<0.05)$.

It is thus implied that kefir causes a cell cycle arrest at the G1 transition checkpoint which explains its anti-proliferative effect.

Kefir has a pro-apoptotic effect on Caco-2 and HT-29 cells. To verify if kefir reduce the viability of the CRC cells through an induction of apoptosis, we used the cell death detection ELISA 

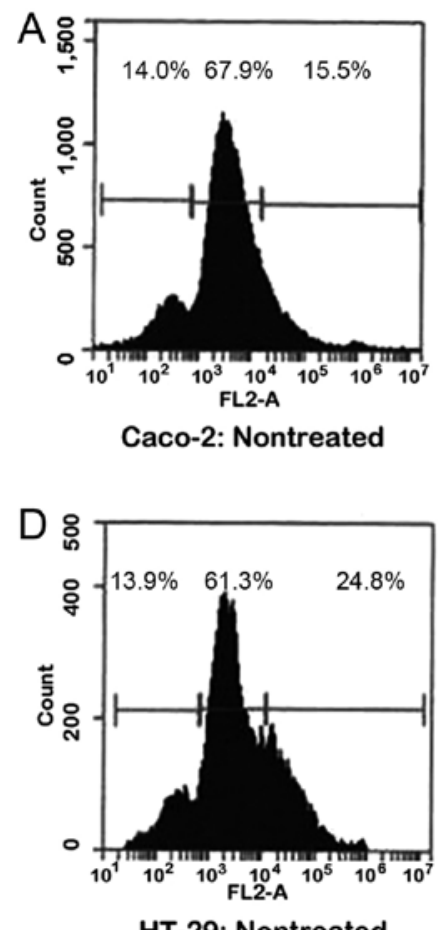

HT-29: Nontreated
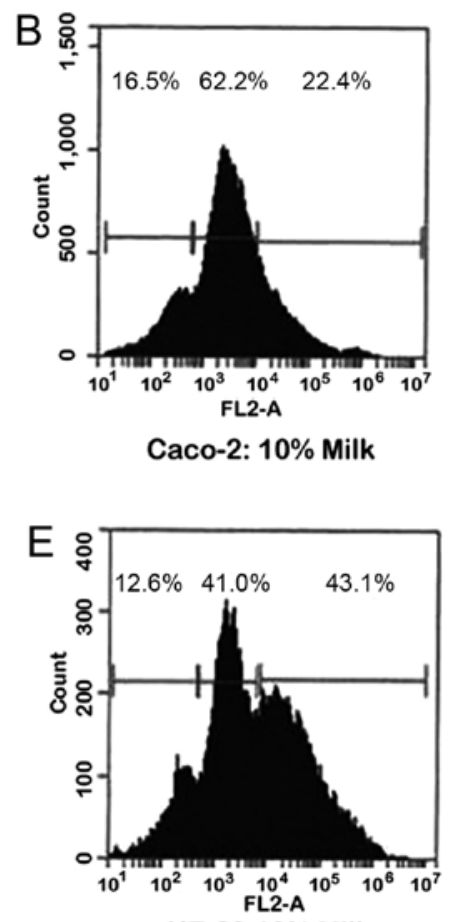

HT-29 10\% Milk

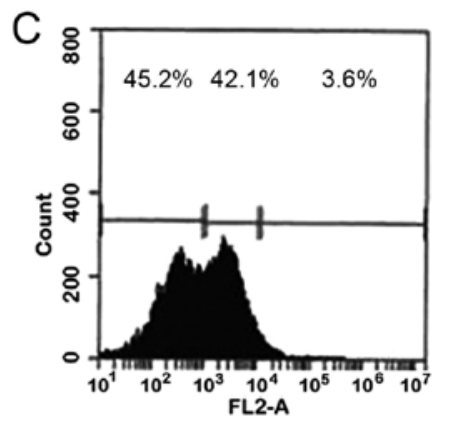

Caco-2: $10 \%$ Kefir

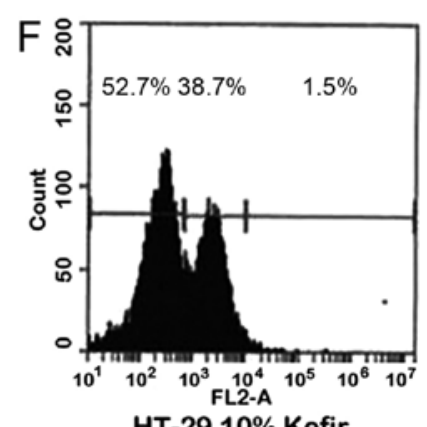

HT-29 10\% Kefir

Figure 3. Cell cycle analysis by flow cytometry of kefir-treated colorectal cancer (CRC) cells. Cell cycle analysis for Caco-2 cells after $24 \mathrm{~h}$ of treatment with (A) $0 \%$ kefir, (B) 10\% milk, and (C) 10\% kefir. Cell cycle analysis for HT-29 cells after $24 \mathrm{~h}$ of treatment with (D) $0 \%$ kefir, (E) $10 \%$ milk, and (F) $10 \%$ kefir.

assay, where the absorbance obtained at $405 \mathrm{~nm}$ reflects the quantity of released nucleosomes, a hallmark of apoptosis. The $\mathrm{EF}$, which is the ratio of the absorbance measured for each concentration to that of the untreated controls, was calculated. In Caco-2 kefir-treated cells, the EF increased around 2.3-, 2.6-, and 6-fold, $24 \mathrm{~h}$ after treatment with 5, 10, and $15 \%$ kefir, respectively (Fig. 4A). Upon $48 \mathrm{~h}$ of treatment, the calculated EF showed a 3.5-, 4-, and 5.6-fold increase with 5, 10, and 15\% kefir, respectively (Fig. 4B). HT-29 cells also showed a significant increase in apoptosis induction upon kefir treatment. In the 24-h kefir-treated HT-29 cells, the EFs were $\sim 1.9,2.4$, and 6.3 upon treatment with 5, 10, and $15 \%$ kefir, respectively (Fig. 4C). Similarly, after $48 \mathrm{~h}$ of kefir treatment with 5,10 , and $15 \%$ kefir, the EFs were determined to be 1.3 , 2.2, and 5.5, respectively (Fig. 4D). Also, in both cell lines, milk treatment induced a decrease in apoptosis as compared to the untreated controls with an EF $<1$, significantly lower than kefir $(\mathrm{p}<0.05)$ (Fig. 4A-D). The results obtained confirm that the decreased viability resulting from kefir treatment involves the induction of apoptosis.

Kefir modulates the expression of genes involved in proliferation and apoptosis. In order to determine a possible mechanism for the anti-proliferative effect of kefir observed in the CRC cells with the WST-1 assay, the expression of TGF- $\alpha$ and $T G F-\beta 1$ was assessed at the mRNA level using RT-PCR in HT-29 cells. The results showed a significant decrease in the expression of both cytokines in a dose-dependent manner upon kefir treatment in HT-29 cells for $24 \mathrm{~h}$ (Fig. 5A), consistent with the observed reduction in proliferation. The expression of both cytokines did not change in milk-treated cells (Fig. 5B). To examine the mechanism behind kefir's pro-apoptotic effect on CRC cells, the expression of Bax, $\mathrm{Bcl}-2$, p53, and p21 was assessed at the protein level using western blotting in HT-29 cells. Consistent with the induction of apoptosis seen with the cell death assay, we observed an increase in the Bax:Bcl-2 ratio upon kefir treatment, while a slight decrease in this ratio was observed upon milk treatment (Fig. 5C and D). Furthermore, results showed no significant increase in the expression of p53 in kefir-treated cells, yet p21 levels showed an increase upon treatment with $10 \%$ kefir (Fig. 5E). For milk-treated cells, the expression of p53 and p21 does not significantly vary between control and treated cells (Fig. 5F). In addition, we examined the expression of matrix metalloproteinases MMP-2 and MMP-9 in treated HT-29 cells and observed that it was unaffected by either kefir or milk treatment (Fig. 5G and $\mathrm{H}$ ). These results suggest that kefir's anti-proliferative and pro-apoptotic effects involve a reduction in $T G F-\alpha$ and $T G F-\beta 1$, and an upregulation in the Bax:Bcl-2 ratio as well as p53-independent p21 expression, respectively, with no effect on the levels of MMPs.

Kefir treatment does not affect the motility of colon and breast cancer cell lines. The effect of kefir on the metastatic ability of cancer cells was assessed in a single study, in vivo, by Furukawa et al (20). Therefore, we aimed to determine whether there is a direct effect on the motility of cancer cells in vitro upon kefir treatment. Using wound-healing analysis, we observed no significant difference in the migration rate of control and kefir-treated colorectal cells (Caco-2 and HT-29) after $24 \mathrm{~h}$ of treatment ( $\mathrm{p}>0.05$ ) (Fig. 6A-D). We thus decided to explore whether kefir might induce an effect on the motility of other cancer types in vitro. For that purpose, two breast cancer cell lines, MCF-7, whose proliferation has 

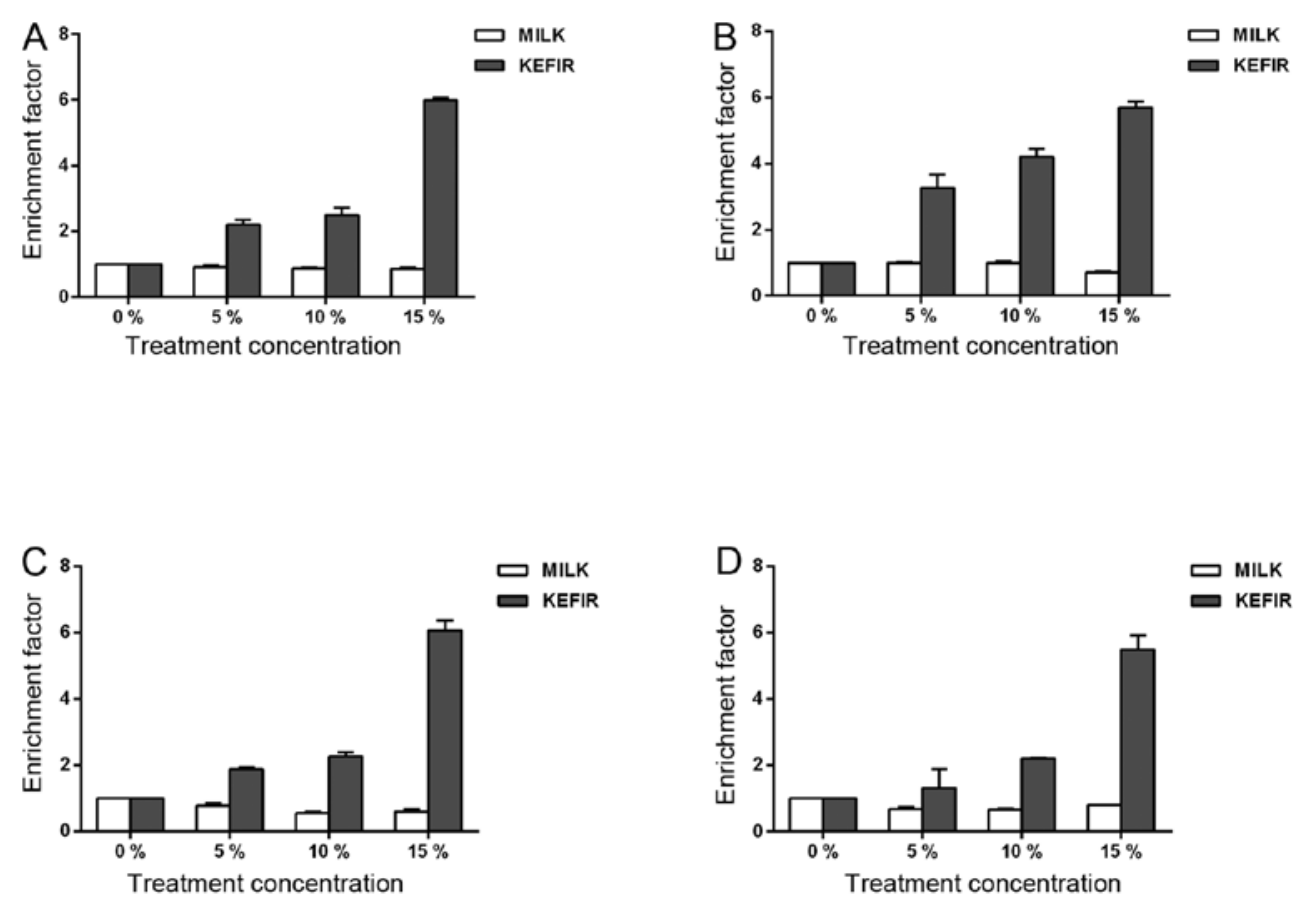

Figure 4. Effect of kefir on apoptosis of colorectal cancer (CRC) cell lines. Induction of apoptosis in Caco-2 cells (A) $24 \mathrm{~h}$ and (B) $48 \mathrm{~h}$ after kefir and milk treatment. Induction of apoptosis in HT-29 cells (C) $24 \mathrm{~h}$ and (D) $48 \mathrm{~h}$ after kefir and milk treatment. Results shown represent the enrichment factor (EF) calculated as absorbance of sample/absorbance of untreated control. Data represent mean \pm SEM from three independent experiments.
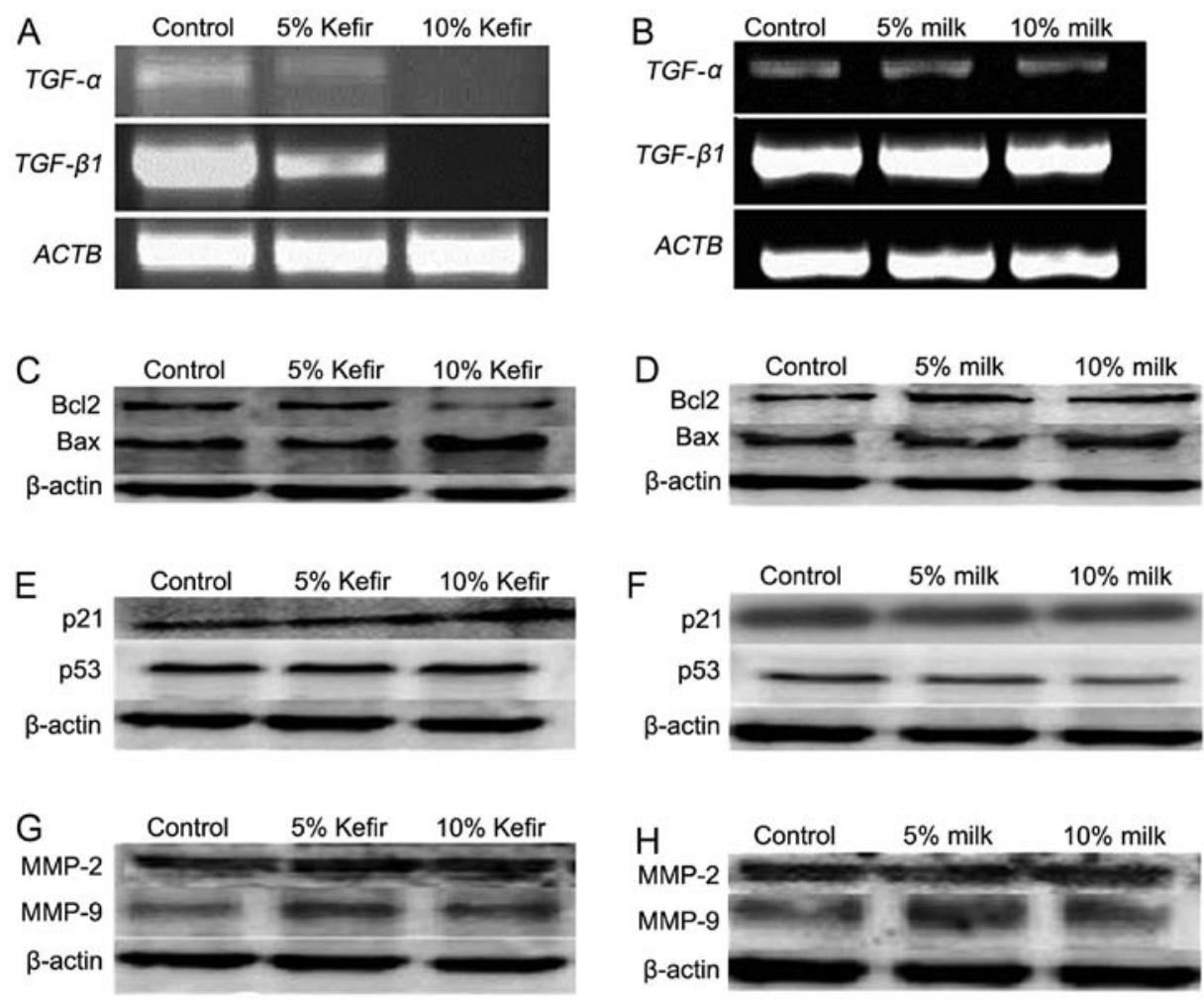

Figure 5. Expression of genes involved in proliferation and apoptosis in kefir-treated HT-29 cells. The expression of transforming growth factor $\alpha$ (TGF- $\alpha$ ) and transforming growth factor- $\beta 1$ (TGF- $\beta 1$ ) in 0, 5, and $10 \%$ (v/v) (A) kefir- and (B) milk-treated HT-29 cells. Representative western blotting images for Bax and Bcl-2 in (C) kefir- and (D) milk-treated cells. Representative western blot images for p21 and p53 in (E) kefir- and (F) milk-treated cells. Representative western blot images for MMP-2 and MMP-9 in (G) kefir and (H) milk-treated cells.

previously been shown to be reduced by kefir treatment by Chen et al (11), and MDA-MB-231 were used. In both of these cell lines, we observed a slight but non-significant $(\mathrm{p}>0.05)$ decrease in the migration ability between control and treated cells (Fig. 6E-H). Kefir's effect on the migration ability of both colorectal and breast cancer cell lines was also assessed 

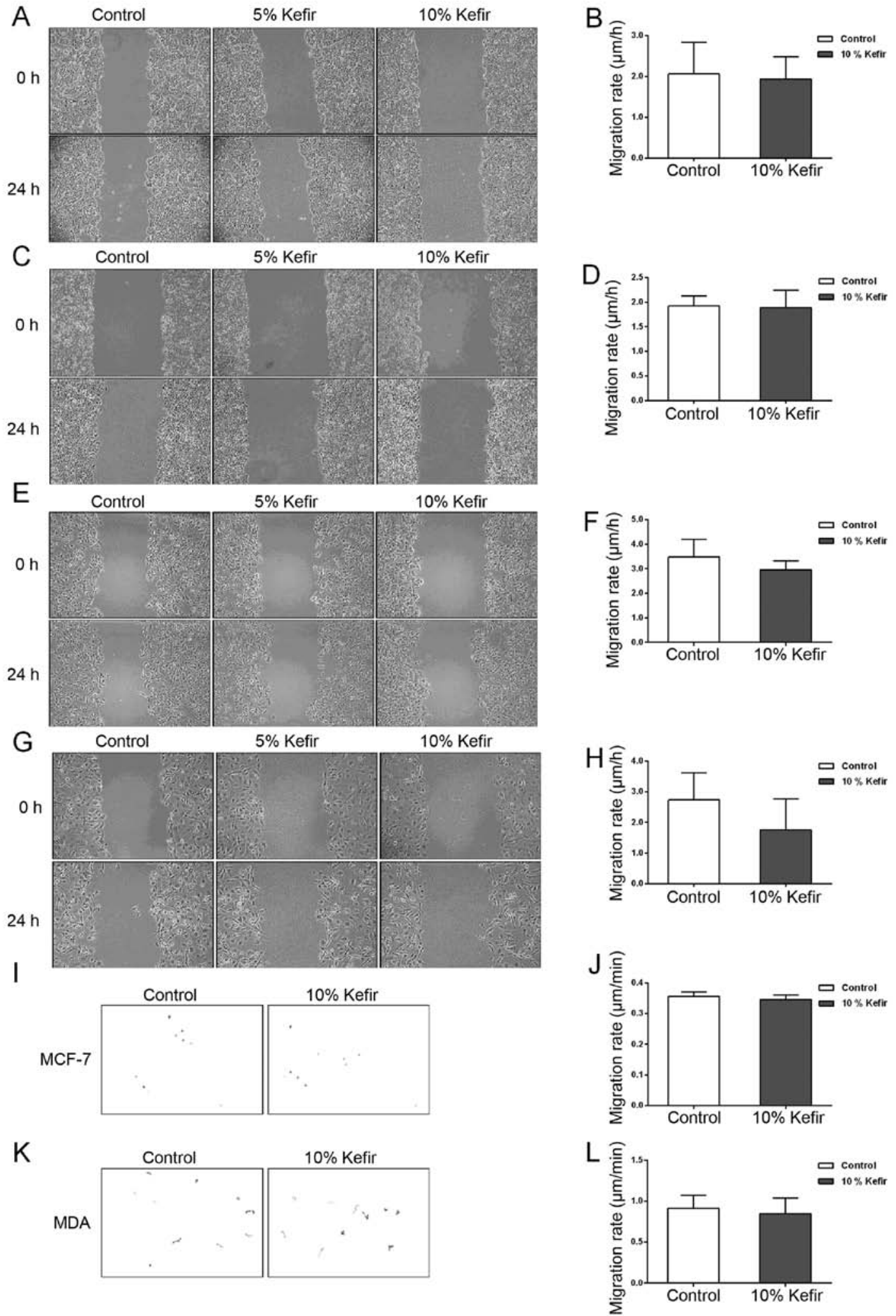

Figure 6. Effect of kefir on the migration ability of treated cells in vitro. (A) Images from the wound-healing assay measuring the motility of HT-29 cells. (B) Quantitation of the migration rate of Fig. 6A. (C) Images from the wound-healing assay measuring the motility of Caco-2 cells. (D) Quantitation of the migration rate of Fig. 6C. (E) Images from the wound-healing assay measuring the motility of MCF-7 cells. (F) Quantitation of the migration rate of Fig. 6E. (G) Images from the wound-healing assay measuring the motility of MDA-MB-231 cells. (H) Quantitation of the migration rate of Fig. 6G. (I) Bar graphs measuring the migration rate for the path traveled by MCF-7 cells in Fig. 6J. (J) Migration path of MCF-7 cells randomly moving in serum complete media for $2 \mathrm{~h}$. (K) Bar graphs measuring the migration rate for the path traveled by MDA-MB-231 cells in Fig. 6L. (L) Migration path of MDA-MB-231 cells randomly moving in serum complete media for $2 \mathrm{~h}$. Data represent mean \pm SEM from three independent experiments.

using time-lapse movies. Consistent with the results of the wound-healing assay, we observed a slight decrease in the migration ability of both cell lines upon kefir treatment, yet the decrease was non-significant (Fig. 6I-L). 

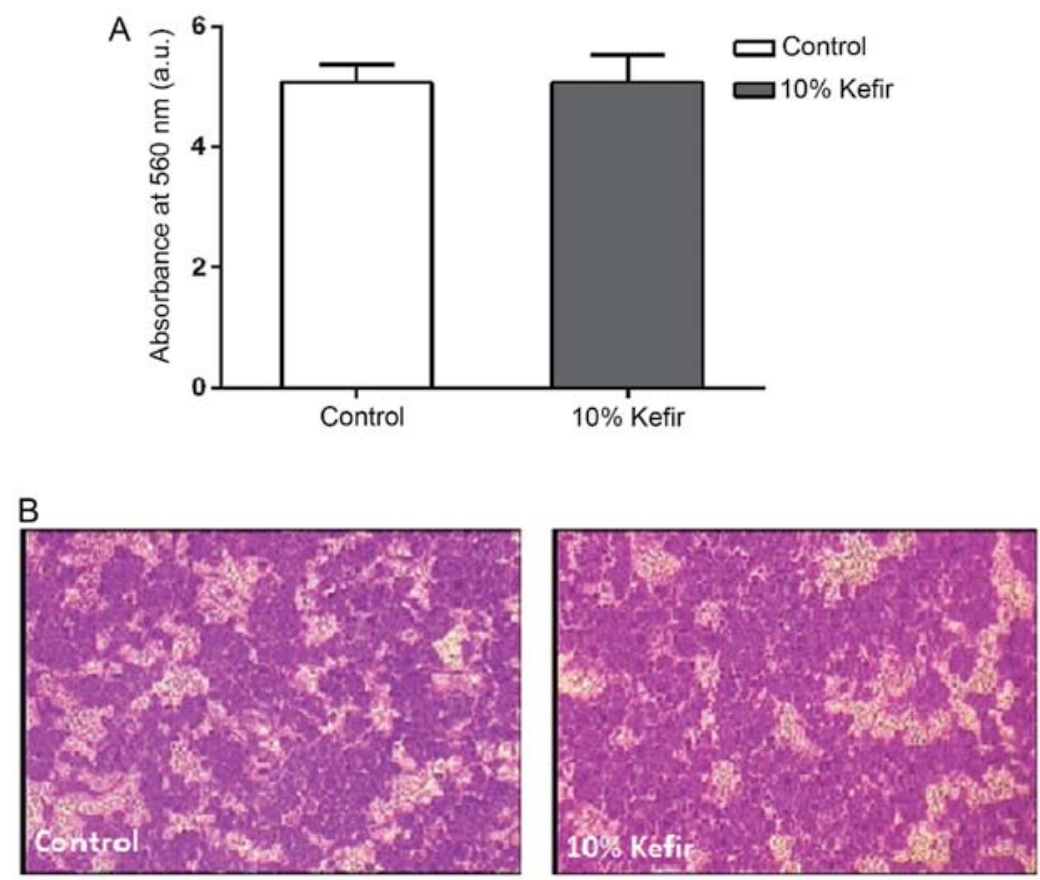

Figure 7. Effect of kefir on the invasive ability of treated HT-29 cells in vitro. (A) Bar graph showing the absorbance of the stain retained by the invasive cells at $560 \mathrm{~nm}$ which reflects the amount of invading cells. Data represent mean \pm SEM from three independent experiments. (B) Representative images showing the collagen invading HT-29 cells in purple.

In vitro invasion of HT-29 cells is not affected by kefir treatment. After looking at the motility of colorectal and breast cancer cell lines in two-dimensions and observing no effect upon kefir treatment, we decided to look at whether kefir has any effect on the invasive ability of the CRC HT-29 cells. Using the collagen-based invasion assay, we observed no significant difference in the invasive ability of HT-29 cell lines between control and $10 \%$ kefir-treated cells in vitro $(\mathrm{p}>0.05)$ (Fig. 7).

\section{Discussion}

In the present study, we aimed to investigate whether kefir's anti-cancerous effect, previously proven on several types of cancers, both in vivo and in vitro, also applies to CRC cell lines. The results obtained are in accordance with previous study on breast and leukemic cancer cell lines, showing an anti-proliferative and pro-apoptotic effect of kefir on these cells $(11,18,19)$.

We first determined that the IC50 is reached with 18 , 12 , and $10 \% \mathrm{v} / \mathrm{v}$ (kefir cell-free fractions) at 24, 48, and $72 \mathrm{~h}$ respectively, for Caco-2 cells, compared to 12 and $10 \%$ at 48 and 72 h, respectively, for HT-29 cells. For both cell lines, treatment with kefir reduced viability in a time- and dose-dependent manner. Since $6 \mathrm{~h}$ post-treatment, the viability of the cell lines was not reduced (data not shown), it was assumed that the cell numbers were reduced due to cell death. The observation that the milk-treated cells showed no decrease in viability suggests that kefir's effect is due to products released by the microorganisms during fermentation.

A notable decrease in proliferation upon kefir treatment was detected in the cells using the WST-1 reagent. Caco- 2 cells exhibited a 91,74 , and $96 \%$ decrease in proliferative activity upon treatment with 18,12 , and $10 \%$ at 24,48 , and $72 \mathrm{~h}$, respectively (IC50 concentrations). For HT-29 cells, treatment with IC50 concentrations (12 and $10 \%$ at 48 and $72 \mathrm{~h}$, respectively), caused 64 and $40 \%$ decrease. As expected, milk-treated cells results showed an increase in proliferation. Through flow cytometry, it was verified that kefir, but not milk, causes a shift in the cell cycle of the treated cells towards the sub-G0/G1 phase, by inducing cell cycle arrest at the G1 checkpoint. Kefir did not only increase the percentage of cells in the sub-G0/G1 phase, but also caused a reduction in the $\mathrm{S} / \mathrm{M}$ cell population as well. The increase in sub-G0/G1 implies that kefir induces death in CRC cell lines. To verify that the cells were dying through apoptosis and not necrosis, as assumed, the cell death ELISA kit assay was performed. The results of this assay confirmed that kefir was indeed inducing apoptosis in Caco-2 and HT-29 cells.

TGF- $\alpha$ is a known mitogen whose expression is upregulated in many types of tumors, especially CRC, where its expression exceeds four times that of normal colorectal tissues (9,31). TGF- $\alpha$ expression was downregulated in HT-29 cells, dose-dependently, upon treatment with non-cytotoxic doses of kefir (5 and 10\%), but not milk. These results are consistent with the observed decrease in proliferation of HT-29 and consistent with a previous study (19). Moreover, given the fact that TGF- $\alpha$ also plays a significant role in invasion and metastasis in vivo, this further shows the importance of targeting it, not only to inhibit cancer growth, but also invasion and metastasis (30,32-34).

A downregulation in the expression level of $T G F-\beta 1$ was also observed in HT-29 cells upon treatment with kefir but not milk. This observation was at first perplexing, as it is not in accordance with a previous study (19). TGF- $\beta 1$ has long been assumed to act as a tumor suppressor yet many studies have 
shown data conflicting with its known role and showed that the response of a cell to TGF- $\beta 1$ is context dependent (35). It has been previously reported that TGF- $\beta 1$ is able to stimulate the growth of HT-29 cells (36). Therefore, the observed decrease in its expression obtained is consistent with the decrease in proliferation upon kefir treatment. In CRC, TGF- $\beta 1$ suppresses immune system cells in the microenvironment, recruits cells that enhance invasion, and stimulates angiogenesis (37-39). Thus, our data might be of great significance given the fact that drugs targeting the TGF- $\beta$ signaling pathway, especially by inhibiting the expression of TGF- $\beta$ have now reached phase III clinical trials $(40,41)$.

To determine a possible explanation for the pro-apoptotic effect of kefir, the expression of Bax and Bcl-2 at the protein level was assessed. Our findings show upregulation in Bax:Bcl-2 expression in HT-29 cells, consistent with the observed increase in apoptosis using the cell death ELISA assay. For the milk-treated HT-29 cells, a decrease in Bax:Bcl-2 ratio was observed which is also in accordance with the decrease in apoptosis and increase in proliferation observed for milk-treated cells.

To further elucidate the mechanism of action of kefir, the expression levels of p53 and p21 proteins were assessed. Kefir treatment at 5 and $10 \%$ (v/v) caused no difference in p53 levels but a noticeable increase in p21 levels when treated with $10 \%$ kefir. This increase in p21 levels might explain the cell cycle arrest observed at the G1 phase through cell cycle analysis by flow cytometry. Our data suggest that p21 induction is p53-independent.

Since metastasis remains the main cause of death in cancer patients, we assessed the effect of cell-free fractions of kefir on the motility of CRC cells in vitro (29). Using wound-healing analysis, no difference in motility between the control and $10 \%$ kefir-treated HT-29 and Caco-2 cells was observed, in contrast to a previous study showing that kefir inhibits metastasis of Lewis lung carcinoma and B16 melanoma in vivo (20). The effect of cell-free fractions of kefir was then assessed on weakly metastatic MCF-7 and highly metastatic MDA-MB-231 breast cancer cell lines. Using both time-lapse movies and wound-healing assays, we noted a non-significant decrease in the motility of these cells. Yet metastasis does not depend only on the motility of the cells, but also involves invasion of the microenvironment, intravasation into vessels, survival in the blood or lymph, extravasion, and colonization at secondary sites (42). Therefore, we decided to look at the effect of kefir on invasion using a collagen-based in vitro assay. A decrease in the invasive ability of HT-29 cells was expected since downregulation in TGF- $\alpha$ and TGF- $\beta 1$, both of which play an important role in enhancing invasion of cancer cells, was observed upon kefir treatment (34-37). However, results showed no difference in the invasive ability between control and $10 \%$ treated cells. Also, the expression of the matrix metalloproteinases MMP-2 and MMP-9, which are required for the degradation of the extracellular matrix, were not altered between control and kefir-treated cells at the protein level. Our data do not rule out the fact that kefir could affect metastasis since it might exhibit an indirect effect inhibiting metastasis in vivo through modulating the immune system or the microenvironment of the cells. Another hypothesis could be that kefir might be intervening in other processes involved in metastasis besides motility and invasion. A third possibility is that components found in kefir might be metabolized in vivo leading to the formation of active compounds which are able to inhibit metastasis.

In conclusion, kefir has become globally known as a complex probiotic, to which many health benefits have been attributed. These include anti-microbial, anti-inflammatory, immunomodulatory, and metabolic benefits. This study focused on assessing kefir's anti-cancerous potential. Through several experiments, we have established that kefir exhibits pro-apoptotic and anti-proliferative properties on colorectal adenocarcinoma cells, namely Caco-2 and HT-29, in vitro. It was also demonstrated that kefir causes cell cycle arrest at G1 phase. The results of our experiments, which were correspondingly performed with milk treatment, affirm that kefir's beneficial effects are due to products produced by the microorganisms during fermentation. This study is the first to elucidate a potential mechanism of action for kefir's effect on CRC in vitro. The downregulation in the expression of $T G F-\alpha$ and $T G F-\beta 1$ explain the decrease in the proliferation of HT-29 cells in vitro. Also the observed overexpression of p21, which was seen to be p53-independent, could be the reason for the cell cycle arrest at the G1 phase observed upon kefir treatment. Moreover, we report that the ratio of Bax:Bcl-2 increases upon kefir treatment consistent with the increase in apoptosis induced by kefir. On the other hand, the effect of kefir on the motility and invasion of CRC cell lines is insignificant, but this does not rule out the fact that kefir could affect the metastatic ability of cancer cells. Kefir's effect on metastasis could be by modulating other steps in the metastatic process or that its effect can only be detected in vivo. Future study will focus on confirming the effect of kefir on the growth of CRC in vivo, and assessing its effect on the metastasis through the intra-splenic injection of HT-29 that causes liver metastasis.

\section{Acknowledgements}

ROI tracker software was supplied by David Entenberg and John Condeelis as supported by CA100324 and GM064346. This study was partially funded by the National Council for Scientific Research-Lebanon, and the Univeristy Research Council-Lebanese American University.

\section{References}

1. Adriana P and Socaciu C: Probiotic activity of mixed cultures of kefir's lactobacilli and non-lactose fermenting yeasts. Agric 65: 329-334, 2008.

2. Farnworth ER: Kefir - a complex probiotic. Food Sci Technol Bull 2: 1-17, 2005.

3. Angulo L, Lopez E and Lema C: Microflora present in kefir grains of the Galician region (north-west of Spain). J Dairy Res 60: 263-267, 1993.

4. Lopitz-Otsoa F, Rementeria A, Elguezabal N and Garaizar J: Kefir: a symbiotic yeasts-bacteria community with alleged healthy capabilities. Rev Iberoam Micol 23: 67-74, 2006.

5. Simova E, Simov Z, Beshkova D, Frengova G, Dimitrov Z and Spasov Z: Amino acid profiles of lactic acid bacteria, isolated from kefir grains and kefir starter made from them. Int J Food Microbiol 107: 112-123, 2006.

6. Liu JR, Wang SY, Lin YY and Lin CW: Antitumor activity of milk kefir and soy milk kefir in tumor-bearing mice. Nutr Cancer 44: 182-187, 2002. 
7. Vinderola G, Perdigón G, Duarte J, Farnworth E and Matar C: Effects of the oral administration of the exopolysaccharide produced by Lactobacillus kefiranofaciens on the gut mucosal immunity. Cytokine 36: 254-260, 2006.

8. Hertzler SR and Clancy SM: Kefir improves lactose digestion and tolerance in adults with lactose maldigestion. J Am Diet Assoc 103: 582-587, 2003.

9. Liu JR, Wang SY, Chen MJ, Chen HL, Yueh PY and Lin CW: Hypocholesterolaemic effects of milk-kefir and soyamilk-kefir in cholesterol-fed hamsters. Br J Nutr 95: 939-946, 2006.

10. Preidis GA, Hill C, Guerrant RL, Ramakrishna BS, Tannock GW and Versalovic J: Probiotics, enteric and diarrheal diseases, and global health. Gastroenterology 140: 8-14, 2011.

11. Chen C, Chan HM and Kubow S: Kefir extracts suppress in vitro proliferation of estrogen-dependent human breast cancer cells but not normal mammary epithelial cells. J Med Food 10: 416-422, 2007

12. Rodrigues KL, Caputo LR, Carvalho JC, Evangelista J and Schneedorf JM: Antimicrobial and healing activity of kefir and kefiran extract. Int J Antimicrob Agents 25: 404-408, 2005.

13. Shiomi M, Sasaki K, Murofushi M and Aibara K: Antitumor activity in mice of orally administered polysaccharide from Kefir grain. Jpn J Med Sci Biol 35: 75-80, 1982.

14. Murofushi M, Shiomi M and Aibara K: Effect of orally administered polysaccharide from kefir grain on delayed-type hypersensitivity and tumor growth in mice. Jpn J Med Sci Biol 36: 49-53, 1983.

15. Murofushi M, Mizuguchi J, Aibara K and Matuhasi T: Immunopotentiative effect of a polysaccharide from kefir grain, KGF-C, administered orally in mice. Immunopharmacology 12 : 29-35, 1986.

16. Furukawa N, Matsuoka A and Yamanaka Y: Effects of orally administered yoghurt and kefir on tumor growth in mice. J Jpn Soc Nutr Food Sci 43: 450-453, 1990.

17. Kubo M, Odani T, Nakamura S, Tokumaru S and Matsuda $\mathrm{H}$ Pharmacological study on kefir - a fermented milk product in Caucasus. I. On antitumor activity (1). Yakugaku Zasshi 112: 489-495, 1992 (In Japanese).

18. Rizk S, Maalouf K and Baydoun E: The antiproliferative effect of kefir cell-free fraction on HuT-102 malignant T lymphocytes Clin Lymphoma Myeloma (Suppl 3): S198-S203, 2009.

19. Maalouf K, Baydoun E and Rizk S: Kefir induces cell-cycle arrest and apoptosis in HTLV-1-negative malignant T-lymphocytes. Cancer Manag Res 3: 39-47, 2011.

20. Furukawa N, Matsuoka A, Takahashi T and Yamanaka Y Anti-metastatic effect of kefir grain components on Lewis lung carcinoma and highly metastatic B16 melanoma in mice. J Agric Sci Tokyo Nogyo Daigaku 45: 62-70, 2000.

21. Siegel R, Naishadham D and Jemal A: Cancer statistics, 2013. Cancer J Clin 2013, 63: 11-30.

22. Hamilton SR: The molecular genetics of colorectal neoplasia. Gastroenterology 105: 3-7, 1993.

23. Hoff G, Foerster A, Vatn MH, Sauar J and Larsen S: Epidemiology of polyps in the rectum and colon. Recovery and evaluation of unresected polyps 2 years after detection. Scand J Gastroenterol 21: 853-862, 1986.

24. Wolpin BM and Mayer RJ: Systemic treatment of colorectal cancer. Gastroenterology 134: 1296-1310, 2008.

25. Messersmith WA and Hidalgo M: Panitumumab, a monoclonal anti-epidermal growth factor receptor antibody in colorectal cancer: another one or the one? Clin Cancer Res 13 4664-4666, 2007.
26. Arteaga C: Targeting HER1/EGFR: a molecular approach to cancer therapy. Semin Oncol (3 Supp 7): S3-S14, 2003.

27. Rodriguez-Bigas MA, Lin EH and Crane CH: Stage IV colorectal cancer. In: Holland-Frei Cancer Medicine. Kufe DW, Pollock RE Weichselbaum RR, Bast RC, Gansler TS, Holland JF and Frei E (eds). Vol 2. 6th edition. Hamilton, ON, 2003.

28. Hassan MS, Ansari J, Spooner D and Hussain SA: Chemotherapy for breast cancer (Review). Oncol Rep 24: 1121-1131, 2010.

29. Palmer TD, Ashby WJ, Lewis JD and Zijlstra A: Targeting tumor cell motility to prevent metastasis. Adv Drug Deliv Rev 63: $568-581,2011$

30. Ji H, Zhao X, Yuza Y, Shimamura T, Li D, Protopopov A, Jung BL, McNamara K, Xia H, Glatt KA, et al: Epidermal growth factor receptor variant III mutations in lung tumorigenesis and sensitivity to tyrosine kinase inhibitors. Proc Natl Acad Sci USA 103: 7817-7822, 2006

31. Liu C, Woo A and Tsao MS: Expression of transforming growth factor-alpha in primary human colon and lung carcinomas. Br J Cancer 62: 425-429, 1990

32. Sasaki T, Nakamura T, Rebhun RB, Cheng H, Hale KS, Tsan RZ, Fidler IJ and Langley RR: Modification of the primary tumor microenvironment by transforming growth factor alpha-epidermal growth factor receptor signaling promotes metastasis in an orthotopic colon cancer model. Am J Pathol 173: 205-216, 2008

33. Ueda M, Fujii H, Yoshizawa K, Terai Y, Kumagai K, Ueki K and Ueki M: Effects of EGF and TGF-alpha on invasion and proteinase expression of uterine cervical adenocarcinoma OMC-4 cells. Invasion Metastasis 18: 176-183, 1998.

34. Hölting T, Siperstein AE, Clark OH and Duh QY: Epidermal growth factor (EGF)-and transforming growth factor alpha-stimulated invasion and growth of follicular thyroid cancer cells can be blocked by antagonism to the EGF receptor and tyrosine kinase in vitro. Eur J Endocrinol 132: 229-235, 1995

35. Massagué J: TGF $\beta$ signalling in context. Nat Rev Mol Cell Biol 13: 616-630, 2012.

36. Halder SK, Beauchamp RD and Datta PK: A specific inhibitor of TGF-beta receptor kinase, SB-431542, as a potent antitumor agent for human cancers. Neoplasia 7: 509-521, 2005.

37. Xiong B, Yuan HY, Hu MB, Zhang F, Wei ZZ, Gong LL and Yang GL: Transforming growth factor-betal in invasion and metastasis in colorectal cancer. World J Gastroenterol 8: 674-678, 2002

38. Thiery JP, Acloque H, Huang RY and Nieto MA: Epithelial-mesenchymal transitions in development and disease. Cell 139: 871-890, 2009.

39. Ramesh S, Wildey GM and Howe PH: Transforming growth factor beta (TGFbeta)-induced apoptosis: the rise and fall of Bim. Cell Cycle 8: 11-17, 2009.

40. Akhurst RJ and Hata A: Targeting the TGF $\beta$ signalling pathway in disease. Nat Rev Drug Discov 11: 790-811, 2012.

41. Morris JC, Shapiro GI, Tan AR, Lawrence DP, Olencki TE, Dezube BJ, Hsu FJ, Reiss M and Berzofsky JA: Phase I/II study of GC1008: a human anti-transforming growth factor-beta (TGF $\beta$ ) monoclonal antibody (MAb) in patients with advanced malignant melanoma (MM) or renal cell carcinoma (RCC). J Clin Oncol 26 (Suppl 15): S9028, 2008.

42. Fidler IJ: The pathogenesis of cancer metastasis: the "seed and soil' hypothesis revisited. Nat Rev Cancer 3: 453-458, 2003. 